\title{
Tissue Microarrays: Construction and Uses
}

\author{
Carol B. Fowler, Yan-Gao Man, Shimin Zhang, Timothy J. O'Leary, \\ Jeffrey T. Mason, and Robert E. Cunningham
}

\begin{abstract}
Tissue microarrays (TMAs) are produced by taking small punches from a series of paraffin-embedded (donor) tissue blocks and transferring these tissue cores into a positionally encoded array in a recipient paraffin block. Though TMAs are not used for clinical diagnosis, they have several advantages over using conventional whole histological sections for research. Tissue from multiple patients or blocks can be examined on the same slide, and only a very small amount of reagent is required to stain or label an entire array. Multiple sections (100-300) can be cut from a single array block, allowing for hundreds of analyses per microarray. These advantages allow the use of TMAs in high-throughput procedures, such as screening antibodies for diagnostics and validating prognostic markers that are impractical using conventional whole tissue sections. TMAs can be used for immunohistochemistry, immunofluorescence, in situ hybridization, and conventional histochemical staining. Finally, several tissue cores may be taken without consuming the tissue block, allowing the donor block to be returned to its archive for any additional studies.
\end{abstract}

Key words: Fluorescence in situ hybridization, Formalin-fixed, paraffin-embedded, Hematoxylin and eosin, HER-2 gene, Tissue microarray, TMA

\section{Introduction}

Tissue microarrays (TMAs) were first described by Wan et al. (1), and are constructed by transferring small tissue punches from formalin-fixed, paraffin-embedded (FFPE) tissue blocks to spatially fixed positions in a recipient block. The method was further developed by Kononen et al. (2) and Camp et al (3). In recent years, high-density TMAs have become a standard laboratory tool for identifying and validating diagnostic and prognostic biomarkers for a variety of diseases, such as breast cancer $(3,4)$, gastrointestinal tumors $(5)$, prostate cancer $(6,7)$, and lung cancer $(8)$. 

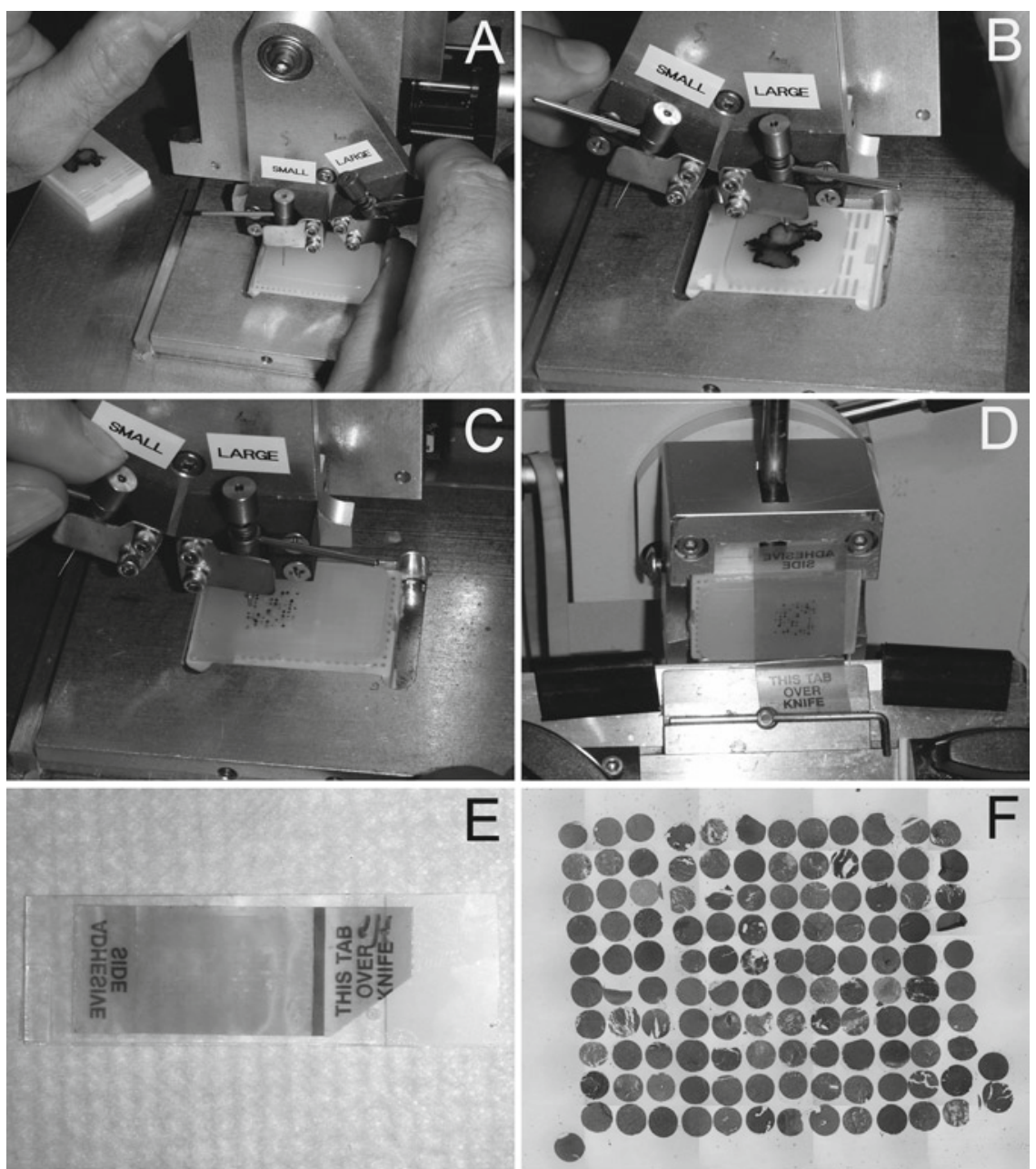

Fig. 1. A general method for tissue microarray construction: (a) a blank recipient block is prepared and cored. (b) A 0.6-mm tissue punch is extracted from the donor block, then (c) relocated to the prepared hole in the recipient block. (d) To section the TMA, a tape window is applied to the TMA, and a $5-\mu \mathrm{m}$ section is cut using a conventional microtome. (e) The tape window is applied to an adhesive-coated slide, and the adhesive is cured under UV light (not shown). (f) An H\&E-stained TMA section (2.5× magnification).

For a comprehensive review of tissue array techniques and applications, see Eguíluz et al. (9).

A general scheme for constructing TMAs is shown in Fig. 1. First, the region of interest is identified on a donor tissue block. A hematoxylin and eosin (H\&E)-stained slide serves as a useful guide for selecting the area to be sampled. Next, a small $(0.6-3 \mathrm{~mm})$ punch is taken from the donor tissue block and seated into a recipient paraffin block in a positionally encoded array format. The tissue punches can be taken with a manual or automatic tissue arrayer, such as those manufactured by Beecher Instruments (Sun Prairie, WI). Once the TMA is constructed, it 
can be sectioned, and mounted on a microscope slide. The TMA can then be stained using a standard histochemical method (i.e., $\mathrm{H} \& \mathrm{E}$ ), or more commonly used for immunohistochemical, immunofluorescence, or fluorescence in situ hybridization (FISH) studies. An example of using FISH with TMAs is for the analysis of HER-2 amplification in breast tumors.

The HER-2 gene, which maps to $17 \mathrm{q} 21.1$, is amplified in $\sim 20 \%$ of breast cancers (10) leading to an overexpression of its protein product, human epithelial growth factor receptor 2 , a cell surface tyrosine kinase receptor. Such cancers are receptive to a targeted therapy by the monoclonal antibody trastuzumab (Herceptin). Accordingly, the accurate assessment of HER-2 status is critical to predict the responsiveness of breast cancer to adjuvant treatment with trastuzumab. Determination of HER-2 status is usually carried out by FISH with whole tissue sections using hybridization probes for the HER-2 gene and a reference hybridization probe for the centromere of chromosome 17 (11). A tumor with a HER-2/chromosome 17 ratio of $>2.2$ is considered to be positive for HER-2 amplification (10). Several recent studies have compared whole sections and TMAs for the assessment of HER-2 status using FISH $(12,13)$. These studies concluded that the use of TMAs to assess HER-2 status gave comparable results to the current standard methodology using whole sections. In addition, these studies demonstrated that TMA technology offered improvements in cost, time, and quality control. A procedure for performing FISH for HER-2 status using a TMA will be described later in the chapter.

Once stained, TMAs may be analyzed in one of two ways. Biomarker expression can be manually assessed using an ordinal grading scale. Though this method has been used for a number of microarray studies, it is time-consuming, semiquantitative, and requires an experienced observer. Dedicated TMA readers and analysis software can improve and simplify the evaluation of TMAs, while streamlining data archiving. Automated analysis protocols can select the region of interest and normalize it so that expression levels can be compared, both between different tissue cores on the same array slide and between different array slides. Some systems use immunofluorescent substrates, while others use chromogenic substrates to quantify biomarkers. Localization of disease biomarkers is usually achieved by counterstaining the TMA with H\&E, then the automated systems use morphometric analyses to distinguish the tumor from normal cellular features. A partial list of available TMA analysis software and slide readers is shown in Table 1. Some of these systems have dedicated applications for HER-2, estrogen receptor, or progesterone receptor [i.e., Automated Cellular Imaging System (ACIS III), AQUA (14), and Pathological Image Analysis and Management (PATHIAM)]. 


\section{Table 1}

\section{Available tissue microarray analysis tools}

\section{TMA analysis system}

\begin{tabular}{|ll}
\hline $\begin{array}{l}\text { Automated Cellular Imaging System } \\
\left.\text { (ACIS }{ }^{\circledR} I I I\right)\end{array}$ & $\begin{array}{l}\text { Dako North America, Inc., Carpinteria, CA } \\
\text { http://www.dakousa.com }\end{array}$ \\
\hline $\begin{array}{c}\text { Automated Quantitative Analysis Software } \\
\text { AQUAnalysis }{ }^{\mathrm{TM}} \text { and AQUAsition }\end{array}$ & $\begin{array}{l}\text { HistoRx, New Haven, CT } \\
\text { http://www.historx.com/ }\end{array}$ \\
\hline $\begin{array}{c}\text { TMA Lab and ScanScope slide scanning } \\
\text { systems }\end{array}$ & $\begin{array}{l}\text { Aperio Technologies, Inc., Vista, CA } \\
\text { http://www.aperio.com/ }\end{array}$ \\
\hline $\begin{array}{c}\text { Pathological Image Analysis and Management } \\
\text { (PATHIAM) }\end{array}$ & $\begin{array}{l}\text { Bioimagene, Inc., San Jose, CA } \\
\text { http://www.bioimagene.com/ }\end{array}$ \\
\hline $\begin{array}{c}\text { Alpha Scan microarray scanner and Image } \\
\text { Acquisition and Analysis software }\end{array}$ & $\begin{array}{l}\text { Alpha Innotech Corp., San Leandro, CA } \\
\text { http://www.cellbiosciences.com/ }\end{array}$ \\
\hline TMA deconvoluter/Stainfinder (15) & http://genome-www.stanford.edu/TMA/ \\
\hline
\end{tabular}

\section{Materials}

\subsection{Construction of the Tissue Microarray}

2.3. Clearing and Rehydrating Slides for Staining
1. Paraplast Tissue Embedding Media (Oxford Labware, St. Louis, MO) or similar. Hold the paraffin at $60^{\circ} \mathrm{C}$ prior to use.

2. Slotted tissue cassettes (Tissue-Tek, Sakura Finetek, Torrance, CA).

3. Base molds up to $37 \times 24 \times 5 \mathrm{~mm}$ (Tissue-Tek).

4. "Donor" blocks with paraffin-embedded tissue of interest (see Note 1).

5. H\&E-stained slides corresponding to the paraffin blocks of interest (see Note 1).

1. Adhesive-coated microscope slides (Paraffin-Tape Transfer Slides, Instrumedics, Inc., St. Louis, MO).

2. Tape windows for section transfer (Instrumedics, Inc.).

3. TPC SOLVENT ${ }^{\mathrm{TM}}$ for removing the tape window and adhesive (Instrumedics, Inc.).

1. Coplin jars for slide incubation (Fisher Scientific, Pittsburgh, PA).

2. Xylene (Sigma-Aldrich, St. Louis, MO) (see Note 2).

3. $100 \%$ Ethanol (Sigma-Aldrich) used to prepare the graded series of alcohols $(100,95,70$, and $30 \%)$ for tissue rehydration.

4. Distilled water. 


\subsection{Hematoxylin and Eosin Staining}

2.5. Fluorescence In Situ Hybridization
1. Coplin jars for slide incubation (Fisher).

2. Mayer's hematoxylin solution (Sigma-Aldrich). Protect from light (see Note 3 ).

3. EosinY with phloxine solution (Sigma-Aldrich; see Note 4).

4. Xylene (Sigma-Aldrich; see Note 2).

5. 100\% Ethanol (Sigma-Aldrich) used to prepare the 95 and $80 \%$ ethanol solutions.

6. Distilled water.

7. Permount mounting media (Fisher).

8. Glass coverslips (Fisher).

1. Coplin jars for slide incubation during the pretreatment, protease, and rinse steps (Fisher).

2. Pretreatment solution: I M sodium thiocyanate (SigmaAldrich), preheated to $97^{\circ} \mathrm{C}$ in a water bath.

3. Protease buffer: $0.9 \%(\mathrm{w} / \mathrm{v})$ sodium chloride (Sigma-Aldrich). Adjust to $\mathrm{pH} 2$ with $\mathrm{HCl}$ and preheat to $37^{\circ} \mathrm{C}$ in a water bath.

4. Pepsin, porcine $(50 \mathrm{mg} / \mathrm{mL})$, from Sigma-Aldrich $(3,200-$ 4,500 AU/mg protein).

5. Sodium chloride/sodium citrate buffer (SSC, $2 \times$ ): $17.5 \mathrm{~g}$ sodium chloride, $8.8 \mathrm{~g}$ SSC (Sigma-Aldrich) in $1 \mathrm{~L}$ distilled water. Adjust the $\mathrm{pH}$ to 7.0 .

6. Distilled water.

7. Fluorescent DNA probes [Vysis LSI HER-2/neu (red) and CEP 17 (green), Abbot Molecular, Inc., Des Plaines, IL]. Protect from light.

8. Posthybridization buffer I: $2 \times$ SSC with $0.3 \%(v / v)$ NP-40 (Sigma-Aldrich).

9. Posthybridization buffer II: $2 \times$ SSC with $0.1 \%(\mathrm{v} / \mathrm{v}) \mathrm{NP}-40$.

10. Glass coverslips (Fisher).

11. Rubber cement (Fisher).

12. Clear nail polish (Fisher).

13. Vectashield mounting media with DAPI (4', 6-diamidino2-phenylindole, Vector Laboratories, Burlingame, CA). Store at $4^{\circ} \mathrm{C}$ in the dark.

\section{Methods}

3.1. Construction of the Tissue

Microarray
1. This protocol assumes the use of a manual tissue arrayer such as the MTA I from Beecher Instruments (Sun Prairie, WI), shown in Fig. 1. Other arrayers may be configured differently and their manual should be consulted prior to use (see Note 5 ). 
2. Prepare an empty, "recipient," paraffin block by pouring liquid paraffin into a stainless steel base mold. Cover with a slotted tissue cassette and allow to cool. Remove the recipient block from the mold and inspect the paraffin surface for any bubbles or holes. Trim any excess paraffin from the plastic cassette.

3. Identify regions of interest from the donor tissue blocks (see Note 1).

4. Determine the desired layout of the TMA and prepare a corresponding positional chart (TMA block summary) to record all of the pertinent information about each tissue core in the array (see Note 6).

5. Using an empty paraffin block, check the alignment of the two punches of the MTA I arrayer. The circular indents made by the small (recipient) and large (donor) punches on the paraffin block surface should have identical centers if they are properly aligned. If necessary, adjust the alignment of the punches as described in the manual.

6. Place the recipient block in the block holder. Adjust the depth stop by tightening the adjustment nut until the punch stops at the desired depth within the paraffin block, typically 0.5-1 $\mathrm{mm}$ above the base of the plastic tissue cassette.

7. Using the smaller punch, make a hole in the first position of the array (i.e., position Al). All other array positions will be in reference to this first spot. Accordingly, set the $\mathrm{X}$ and $\mathrm{Y}$ micrometers of the MTA I to zero. When the depth stop blocks the downward motion, slowly release the tissue punch. Eject the paraffin core.

8. Place the donor block bridge over the array block holder, and move the larger punch into the sampling position. Manually hold the donor block in position on top of the donor block bridge while positioning the area to be sampled directly underneath the sample punch (see Note 7).

9. Push downward on the sample punch to retrieve the tissue core. Note that the depth stop will not block the punch motion at the proper position for the donor block, so care must be taken to prevent the punch from entering too deeply into the block (see Note 8).

10. Remove the donor tissue block and bridge and push the punch downward until its tip reaches the top of the hole in the recipient array block. Use the large punch stylet to inject the tissue core into the hole created by the smaller punch.

11. Adjust the micrometers to move the tissue punch to the next $\mathrm{X}, \mathrm{Y}$ position. A spacing of $0.8-1 \mathrm{~mm}$ between sample centers is customary (see Note 5 ). 


\subsection{Sectioning of the Tissue Microarray}

\subsection{Clearing and Rehydrating Slides for Staining}

\subsection{Hematoxylin and Eosin Staining}

12. Repeat steps 7-11, using the remaining donor tissue blocks, to construct the entire TMA.

13. Once the microarray is constructed, press the TMA block, paraffin side down, lightly on a flat surface to seat the tissue cores.

1. This protocol assumes the use of the Paraffin-Tape Transfer System from Instrumedics, Inc. (see Note 9).

2. To section the TMA, apply a tape window, adhesive side down, onto the surface of the TMA. Gently roll or press the tape window to remove any wrinkles or air bubbles.

3. Place the tissue block on a standard microtome, positioning the leading edge of tape window over the microtome blade. Cut a 5- $\mu \mathrm{m}$ section. A microarray block may yield 100-300 sections, depending upon core depth (see Note 10).

4. Press the tape window, with the TMA section facing downward, onto the adhesive-coated microscope slide. Use the roller to gently remove any air bubbles.

5. Place the tape-covered slide under a UV lamp for 30-60 s to cure the adhesive.

6. Place the slide in the TPC SOLVENT (TM) for $3 \mathrm{~min}$. Carefully peel away the tape window. The TMA slide is now ready for clearing and staining.

1. Incubate the TMA slide through three changes of xylene, 2 min each, to clear the paraffin.

2. Rehydrate the slide through two changes each of $100,95,70$, and $30 \%$ ethanol, 2 min each.

3. Place the slide in distilled water prior to staining (see Subheading 3.4 or 3.5 ).

Adapted from the AFIP Laboratory Methods in Histotechnology (16).

1. Once the TMA slide is cleared and rehydrated, stain for 4-15 min in the Mayer's hematoxylin solution.

2. Remove the slide from the stain and wash in lukewarm running tap water for $15 \mathrm{~min}$.

3. Transfer the slide to distilled water until ready for eosin staining.

4. Rinse the slide in $80 \%$ ethanol for $1-2 \mathrm{~min}$.

5 . Counterstain in the eosin-phloxine solution for $1-2 \mathrm{~min}$.

6. Dehydrate through two changes each of $95 \%$ ethanol, $100 \%$ ethanol, and xylene. Each incubation is for $2 \mathrm{~min}$.

7. Mount with a xylene-based mounting media, such as Permount. 


\subsection{Fluorescence In Situ Hybridization}

1. This protocol is for detecting the amplification of the HER-2 gene by FISH in FFPE breast cancer tissues, but can be adapted for other genes. Individual probe concentrations will need to be optimized. For an example of a TMA slide stained positive for HER-2 gene amplification, see Fig. 2.

2. Remove the TMA slide from the distilled water (Subheading 3.3, step 3) and incubate in the pretreatment solution for $20 \mathrm{~min}$ at $97^{\circ} \mathrm{C}$.

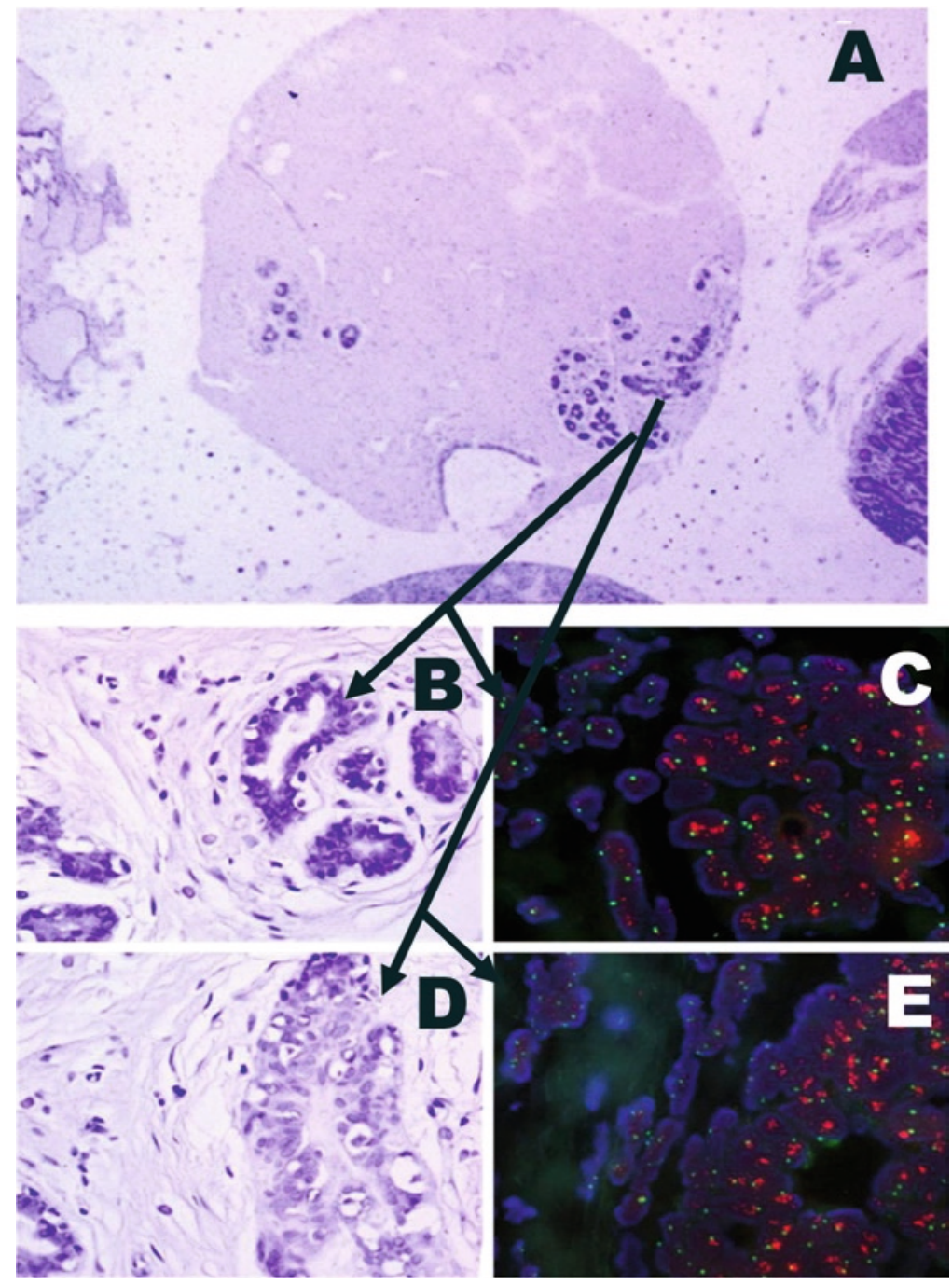

Fig. 2. Dual-color FISH showing that the HER-2 gene is locally amplified in a breast carcinoma. (a) A single H\&E-stained TMA core, 40× magnification. (b) and (d) Selected areas at $400 \times$ magnification, and their corresponding FISH images (c) and (e). The Vysis HER-2 probe system was purchased from Abbot Molecular, Inc. The red HER-2 probe detects the HER-2 gene and the green Cep 17 probe is an internal control for chromosome 17. In normal breast cells, there are two green and two red probe signals per cell. The ratio between the red and green probe signals determines the HER-2 status of the tissue. 
3. Remove the slide from the pretreatment solution and allow it to cool for $2 \mathrm{~min}$. Rinse with distilled water.

4. Add $600 \mu \mathrm{L}$ of the pepsin solution to $55 \mathrm{~mL}$ of prewarmed protease buffer.

5. Incubate the slide in the protease solution for $25 \mathrm{~min}$ at $37^{\circ} \mathrm{C}$.

6. Wash the slide in $2 \times$ SSC, two times, 5 min each. Briefly dip the slide in distilled water.

7. Air-dry the slide or dry on a $42^{\circ} \mathrm{C}$ hot plate.

8. Care should be taken to protect the slide from light for steps 9-19.

9. Denature the amount of Her-2/Cepl7 probe solution equivalent to that required for a standard whole tissue section $(8-10 \mu \mathrm{L})$ in a $74^{\circ} \mathrm{C}$ water bath for $5 \mathrm{~min}$.

10. Add the probe solution to a glass coverslip. Place the pretreated slide, tissue side down, on top of the coverslip and press to remove any air bubbles. Seal the edges of the coverslip with rubber cement.

11. Place the slide in a $37^{\circ} \mathrm{C}$ incubator. Incubate for 6-20 h (see Note 11 for an alternative method).

12. Remove the rubber cement from the coverslip by hand.

13. Soak the slide in posthybridization buffer I at room temperature to release the coverslip.

14. Incubate the slide in posthybridization buffer I for $2 \mathrm{~min}$ at $74^{\circ} \mathrm{C}$.

15. Wash the slide in posthybridization buffer II at room temperature for $30 \mathrm{~s}$.

16. Rinse the slide in distilled water.

17. Air-dry the slide or dry on a $42^{\circ} \mathrm{C}$ hot plate.

18. Add 1-2 drops of Vectashield mounting media with DAPI to a coverslip. Place the slide on top, tissue side down, and press to remove any air bubbles. Seal the edges of the coverslip with clear nail polish.

19. Place the slide in a slide folder and store at $-20^{\circ} \mathrm{C}$ in the dark for at least $30 \mathrm{~min}$ prior to examination using a fluorescence microscope.

\section{Notes}

1. Choosing the correct sampling site from the donor blocks is critical and the most time-consuming step in TMA construction. A fresh H\&E-stained slide from each block should be used as a guide to select the regions of interest for tissue sampling. 
It may be helpful to mark the tissue sampling site on its corresponding slide prior to constructing the microarray. The following criteria for region of interest selection may be helpful:

(a) The tissue block is typically examined by a pathologist to confirm the initial diagnosis and select the most appropriate area(s) in the tissue section for the extraction of the $\operatorname{punch}(\mathrm{es})$.

(b) It is important that the tissue punches should not compromise the diagnostic value of the tissue block. Sufficient material should remain so that a pathologist can confirm the diagnosis and perform additional tests on the tissue. Also, the punches should not compromise the pathologists' ability to appreciate the anatomic relationship between the lesion and the surrounding tissue.

(c) Regions of interest within the tissue block must be $\geq 2 \mathrm{~mm}$ in depth to be used in a TMA.

(d) Regions of interest should not have excessive amounts of necrotic or poorly fixed tissue.

2. Short-term exposure to xylene can cause irritation of the skin, eyes, nose, and throat. Xylene should be handled in a certified chemical fume hood. Alternately, an orange-oil based product, such as Histo-Clear (National Diagnostics; Atlanta, GA) or Hemo-De (Scientific Safety Solvents; Keller, TX) may be used to remove excess paraffin from FFPE tissue sections.

3. Mayer's hematoxylin solution stains the nuclei only. The blue color is enhanced by washing the slide in running tap water. The solution is commercially available, but may be prepared as follows: dissolve $50 \mathrm{~g}$ of ammonium or potassium alum in $1 \mathrm{~L}$ of distilled water, then add $1 \mathrm{~g}$ of hematoxylin crystals. When all of the hematoxylin has been dissolved, add $0.2 \mathrm{~g}$ of sodium iodate and stir for $10 \mathrm{~min}$ before adding $1 \mathrm{~g}$ of citric acid. Stir for an additional $10 \mathrm{~min}$ before adding $50 \mathrm{~g}$ of chloral hydrate. The resulting solution should be a deep "wine red" color.

4. Eosin $\mathrm{Y}$ is a conventional counterstain for hematoxylin and gives a wide range of contrast from pink to bright red. For example, cytoplasm stains pink and collagen and muscle stain bright red. The solution is commercially available, but may be prepared as follows: combine $100 \mathrm{~mL}$ of eosin stock solution ( $1 \mathrm{~g}$ Eosin $\mathrm{Y}$ in $100 \mathrm{~mL}$ in distilled water) with $10 \mathrm{~mL}$ of phloxine stock solution ( $1 \mathrm{~g}$ phloxine $\mathrm{B}$ in $100 \mathrm{~mL}$ distilled water). Add $780 \mathrm{~mL}$ of $95 \%$ ethanol and $4 \mathrm{~mL}$ of glacial acetic acid. The working solution is good for 1 week.

5. Manual tissue arrayers such as the MTA I will allow the average user to take 30-70 tissue punches per hour. Depending upon 
tissue core size and density, recipient blocks can accommodate up to 1,000 samples. Using $0.6 \mathrm{~mm}$ punches, with a spacing of $0.8 \mathrm{~mm}$ between sample centers, the typical array size is 300-500 specimens per block using regular tissue cassettes. Using $2 \mathrm{~mm}$ punches allows construction of tissue arrays with about 50-100 specimens. An automated tissue arrayer can take up to 180 punches per hour $(0.6-3 \mathrm{~mm}$ in size $)$ and can produce up to 26 replicate array blocks in a single run.

6. For array orientation, it may be useful to leave the first position empty, or to substitute with a core taken from a FFPE $3 \%$ agarose-India ink plug. India ink will survive all stages of histology. Figures 3 and 4 show a slide diagram of an 80-core TMA and its corresponding TMA block summary, respectively.

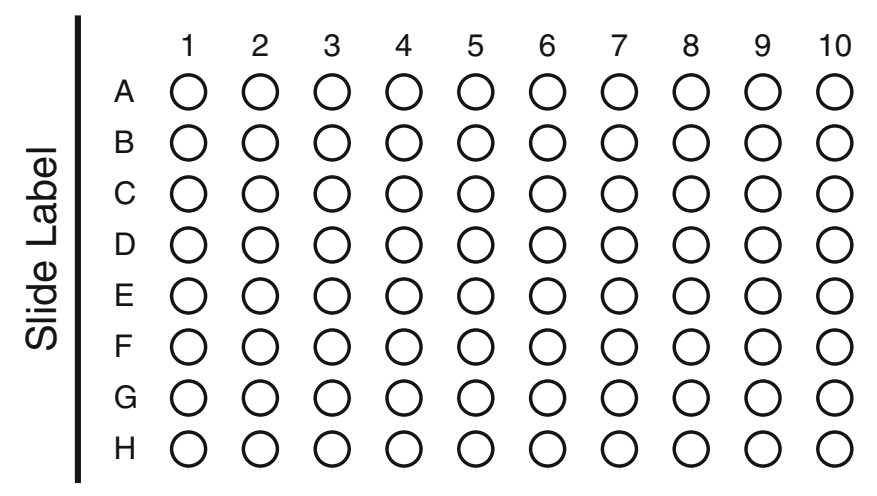

Fig. 3. A slide diagram showing the physical layout of a TMA array on a $1^{\prime \prime} \times 3^{\prime \prime}$. microscope slide. The rows are labeled with letters and the columns are labeled with numbers. The slide diagram shown is for a TMA consisting of an $8 \times 10$ array of tissue cores.

\begin{tabular}{|c|c|c|c|c|c|}
\hline Block ID & Cases & Cores & Layout & Diameter & Section Thickness \\
\hline$\# \# \# \# \# \#$ & $\# \#$ & 80 & 80 & $0.6 \mathrm{~mm}$ & $5 \mu \mathrm{m}$ \\
\hline
\end{tabular}

\begin{tabular}{|c|c|c|c|c|c|c|}
\hline Position & No. & Case No. & Age & Sex & Organ/Tissue & Diagnosis/Type \\
\hline A & 1 & $x x x x x$ & 50 & $F$ & Breast & Her2/neu + \\
\hline A & 2 & $x x x x x$ & 58 & $F$ & Breast & Her2/neu + \\
\hline A & 3 & $x x x x x$ & 60 & $F$ & Breast & Her2/neu - \\
\hline A & 4 & $x x x x x$ & 54 & F & Breast & Her2/neu + \\
\hline A & 5 & $x x x x x$ & 52 & F & Breast & Her2/neu - \\
\hline A & 6 & $x x x x x$ & 45 & F & Breast & Her2/neu + \\
\hline A & 7 & $x x x x x$ & 62 & F & Breast & Her2/neu + \\
\hline A & 8 & $x x x x x$ & 53 & F & Breast & \\
\hline
\end{tabular}

Fig. 4. An example of a format for a TMA block summary, which links the tissue core array position (columns 1 and 2) with the diagnostic details of the corresponding specimen (columns 3-7). 
7. Superimposing the corresponding marked H\&E-stained slide over the tissue block will assist in positioning the area to be sampled underneath the tissue punch. Move the H\&E slide out of the way prior to taking the tissue core.

8. The number of tissue cores sampled per block depends on the tissue type. For example, normal breast epithelium, and other cancers with a high degree of regional heterogeneity will typically require $>2$ punches per block, while most other cancers are well represented with $1-2$ punches (3).

9. TMA sections are most commonly captured onto a tape window and transferred to an adhesive-coated slide. The ParaffinTape Transfer system from Instrumedics minimizes tissue loss and floating of the tissue cores on the slide. It also eliminates the need for a water bath and a $60^{\circ} \mathrm{C}$ incubation step. Sections are immediately ready for deparaffinization. For examples of the tape-transfer system used in the literature, see Camp et al. (3), Kononen et al. (2), or Sauter et al. (17). If conventional microtome sectioning techniques are applied, section quality may be improved by heating the TMA block at $37^{\circ} \mathrm{C}$ for $30 \mathrm{~min}$ and allowing the block to cool to room temperature before sectioning. This process will soften the paraffin helping to anneal the tissue cores to the recipient paraffin block.

10. The first few TMA sections may have missing tissue cores or tears due to uneven seating of the tissue punches in the donor block.

11. Alternatively, undenatured probe may be applied to the pretreated slide (Subheading 3.5, step 10). Once the coverslip is sealed with rubber cement, the slide is incubated in a $74^{\circ} \mathrm{C}$ oven for $5 \mathrm{~min}$, followed by $37^{\circ} \mathrm{C}$ for $6-24 \mathrm{~h}$ before proceeding to the next step (Subheading 3.5, step 12). An automated slide incubator, such as the ThermoBrite ${ }^{\circledR}$ System (Abbot Molecular, Inc.), may also be used for the slide drying and probe hybridization steps.

\section{References}

1. Wan, W. H., Fortuna, M. B., and Furmanski, P. (1987) A rapid and efficient method for testing immunohistochemical reactivity of monoclonal antibodies against multiple tissue samples simultaneously. J Immunol Methods $103,121-9$.

2. Kononen, J., Bubendorf, L., Kallioniemi, A., Barlund, M., Schraml, P., Leighton, S., et al. (1998) Tissue microarrays for high-throughput molecular profiling of tumor specimens. Nat Med. 4, 844-7.

3. Camp, R. L., Charette, L. A., and Rimm, D. L. (2000) Validation of tissue microarray technology in breast carcinoma. Lab Invest. 80, 1943-9.

4. Cryan, J., O'Grady, A., Allen, D., and Kay, E. (2009) Tissue microarray technology in the routine assessment of HER2 status in invasive breast cancer. Histopathology $\mathbf{5 4}, 901$.

5. Cunningham, R. E., Abbondanzo, S. L., Chu, W. S., Emory, T. S., Sobin, L. H., and O'Leary, T. J. (2001) Apoptosis, bcl-2 expression, and p53 expression in gastrointestinal stromal/ smooth muscle tumors. Appl Immunohistochem Mol Morphol. 9, 19-23. 
6. Dhanasekaran, S. M., Barrette, T. R., Ghosh, D., Shah, R., Varambally, S., Kurachi, K., et al. (2001) Delineation of prognostic biomarkers in prostate cancer. Nature 412 , 822-6.

7. Schlomm, T., Iwers, L., Kirstein, P., Jessen, B., Kollermann, J., Minner, S., et al. (2008) Clinical significance of p53 alterations in surgically treated prostate cancers. Mod Pathol. 21, 1371-8.

8. Fernandes, A. P., Capitanio, A., Selenius, M., Brodin, O., Rundlof, A. K., and Bjornstedt, M. (2009) Expression profiles of thioredoxin family proteins in human lung cancer tissue: correlation with proliferation and differentiation. Histopathology 55, 313-20.

9. Eguíluz, C., Viguera, E., Millán, L., and Pérez, J. (2006) Multitissue array review: a chronological description of tissue array techniques, applications and procedures. Pathol Res Pract. 202, 561-8.

10. Carlson, R. W., Moench, S. J., Hammond, M. E., Perez, E. A., Burstein, H. J., Allred, D. C., et al. (2006) HER2 testing in breast cancer: NCCN Task Force report and recommendations. J Natl Compr Canc Netw. 4 Suppl 3, S1-22.

11. Dandachi, N., Dietze, O., and HauserKronberger, C. (2002) Chromogenic in situ hybridization: a novel approach to a practical and sensitive method for the detection of HER2 oncogene in archival human breast carcinoma. Lab Invest. 82, 1007-14.
12. Graham, A. D., Faratian, D., Rae, F., and Thomas, J. S. (2008) Tissue microarray technology in the routine assessment of HER-2 status in invasive breast cancer: a prospective study of the use of immunohistochemistry and fluorescence in situ hybridization. Histopathology 52, 847-55.

13. Faratian, D., Graham, A., Rae, F., and Thomas, J. (2009) Rapid screening of tissue microarrays for Her-2 fluorescence in situ hybridization testing is an accurate, efficient and economic method of providing an entirely in situ hybridization-based Her-2 testing service. Histopathology 54, 428-32.

14. Camp, R. L., Chung, G. G., and Rimm, D. L. (2002) Automated subcellular localization and quantification of protein expression in tissue microarrays. Nat Med. 8, 1323-7.

15. Liu, C. L., Prapong, W., Natkunam, Y., Alizadeh, A., Montgomery, K., Gilks, C. B., et al. (2002) Software tools for high-throughput analysis and archiving of immunohistochemistry staining data obtained with tissue microarrays. Am J Pathol. 161, 1557-65.

16. Allen, T. C. (1992) Hematoxylin and Eosin. In E. B. Prophet, B. Mills, J. B. Arrington, and L. H. Sobin, ed. AIFP Laboratory Methods in Histotechnology, Armed Forces Institute of Pathology, American Registry of Pathology, Washington, DC, 53-58.

17. Sauter, G., Simon, R., and Hillan, K. (2003) Tissue microarrays in drug discovery. Nat Rev Drug Discov. 2, 962-72. 